\title{
Probe into the Elements of Leisure Sports Practice
}

\author{
Kaixian Li \\ Department of Physical Education \\ Nanjing Forestry University \\ Nanjing 210037, China \\ Tel: 86-25-8542-0948 \\ Qun Gao \\ Nanjing Institute of Industry Technology \\ Nanjing 210046, China \\ Tel: 86-25-5245-602
}

\begin{abstract}
This paper probes into the basic elements of leisure sports practice by referencing literature materials and logic analyses. Studies show that leisure sports practice consists of six elements, including leisure sports ideas, leisure sports environment, leisure sports time, leisure sports activity, leisure sports skill, and leisure sports state. All these six elements connect with and restrain one another. Absence of any element will affect the application of leisure sports.
\end{abstract}

Keywords: Leisure sports, Practice, Element

Modern social development and scientific \& technological progresses serve as necessary preconditions (lots of spare time, rich material products, sufficient playgrounds and equipments) for the expansion of leisure sports practice. Meanwhile, changes of production mode and life style (mechanization of work; socialization of housework; reduction of body movements; and over-nutrition) turn leisure sports into a necessary way of relaxation. Leisure sports refer to certain leisure activities that people participate in by initiatives freely for the sake of self-satisfaction and self fulfillment, taking body exercises as basic ways, in certain leisure state and environment. Leisure sports can help to build up a scientific, healthy, and civil life style. Leisure sports practice depends on six elements as follow. All these six elements connect with and restrain one another. Absence of any element will affect the application of leisure sports.

\section{Leisure sports idea}

Leisure sports idea means the understanding and recognition of leisure subjects to leisure sports. It is a kind of leisure thought and leisure faith. Leisure sports aim at relaxing oneself by sports. It is a unification of matters and spirits, bodies and intelligence, physical activities and psychological activities. What it emphasizes is to drive people engaged in favorite sports to realize the spiritual satisfaction, physical relax, and psychological experience. As people are taking leisure sports activities, they perform organic physical movements, such as: the speeds, distances, and directions in completing certain actions, the consumption of body energy, and the expedited flow of blood. But the most prominent is the change of people's spirits in sports. From the fast and changeable action, the accomplishment of actions, the success and failure, the cooperation and competition, the smoothness and frustration, people can taste the interests of sports, and have a sense of self-efficiency, recalling the self, and fulfilling the self. In sports, people can achieve the sublimation of spirits, driving the match of bodies and spirits, and realizing the harmony. To build up correct leisure sports idea can benefit the application of leisure sports.

\section{Leisure sports environment}

Leisure sports environment is the conditions and circumstances in which leisure subjects perform leisure sports activities. It includes natural environment and humanistic environment. Leisure subjects must know and pay attention to the leisure environment. They have to select and adjust appropriate leisure sports activities based on changes of environment. In leisure sports activities, the subject is the leisure subject, and the object includes environment, skill, playground, equipment, and furnishment. Natural environment impacts playgrounds to a great degree. Undoubtedly, plain is not for mountaineering. Surfing must depend on an ocean. Skiing, skating, and ice hockey are right choices in 
cold regions.

Social humanistic environment can also affect leisure sports profoundly. We summarize the culture into mainstream cultures and non-mainstream cultures. The mainstream culture includes traditional cultures and local core cultures. Relatively speaking, mainstream cultures have a decisive effect on leisure activities. People take preferences by following the direction established by mainstream cultures. Local core cultures are also important factors. The so-called local core cultures refer to the cultures that dominate over certain regions, including local customs, ceremonies, social relationship principles, and taboos. Leisure sports may suffer from taboos and customs. Taboos are extremely important in local cultures. They regulate what people should do or should not. In addition, in local core cultures there are some parts that can be used by us properly. Some customs are derived from religious conventions, traditional commercial party, or nationality feasts. In China, a multi-nationality county, lots of local cultures connect with leisure sports, such as holding a goat in mouth, dragon boat match, torch festival, and swing. Although these activities have special meanings and are not the same with the connotation of leisure sports, in forms they serve as sound foundations for local people accepting the leisure sports idea (Feng Lu, 2005, p159-61).

Non-mainstream cultures are new cultures caused by foreign cultures and technological development. Non-mainstream cultures also impact leisure sports greatly. To a great degree, the youth is the main carrier of non-mainstream cultures. For example, bodybuilding is a combination of ancient Grecian aesthetic idea introduced to China in 80s, 20th century, and modern sports. It is widely accepted and gains further development after it enters China. So does the exploration. In exploration, people can relax themselves in nature and learn to live with the nature.

\section{Leisure sports time}

Leisure sports time is the time used for leisure sports by the leisure subject after getting rid of time for work and living. All human activities consume time. The time of human being is divided for different activities. In order to make the time characters clear, we classify the time into different time periods: the work time (used for production work in order to obtain necessary living materials), the living time (the time for normal living, such as time for eating, sleeping, and medical care), and spare time (the time excluding the work time and living time). Leisure sports activities aim at relaxation in spare time. Leisure sports time it the most basic element of leisure sports activities. The rise of modern people's leisure time reflects a kind of progress of social civilization. In modern society, modern scientific and technological development changes modern production mode thoroughly. The improved production efficiency makes the reduction of work time a must. Besides, the continuous update and development of home facilities shortens the housework time sharply. Meanwhile, the socialization of housework also generates lots of leisure time. All these factors contribute the application of leisure sports activities.

\section{Leisure sports activities}

Leisure sports activities are the contents of certain leisure sports selected by leisure subjects. Leisure is the activity or experience in spare time. Leisure activities are "a series of activities by which people can liberate their wills freely after fulfilling their professional, family, and social responsibilities", including rests, self-amusement, improving knowledge and skills, and participating community activities by initiatives. Almost all human activities may be "leisure" activities. But some have higher possibilities. Leisure is not an activity but a process, which concerns certain specific activity inevitably.

Leisure sports can integrate bodies and minds together. Leisure sports activity needs not only minds but also body exercises. It differs essentially from reading, painting, appreciating music, and other leisure activities. In modern social work and living environment, leisure sports can effectively improve body qualities, defending against organic degradation. Meanwhile, because of the diversity of sports, people can achieve their leisure goals by choosing different sports. Sports have positive effects on people's bodies and minds. No matter when it is the past, today, or future, sports are meaningful for people's leisure life. Sports exert effects by re-creation of bodies. Also, leisure sports are not only for amusement or rest but for the positive recovery of humanism and the integration of human being. People should not waste the time liberated from the work and study. For the spare time, leisure sports are the most ideal activities that can adjust body states, driving the harmonious development bodies and minds.

Leisure sports have various activities, such as rock climbing, diving, surfing, and drifting. It demands for not only physical strength, but also intelligence, braveness, and will. People have to exert their initiatives and creativities completely in order to accomplish tough actions. In leisure sports, braveness, brawniness, and struggle spirits, and human feelings and wills are all necessary. However, literature and art leisure activities are almost static, concerning mainly thoughts but not bodies. Compared with other leisure activities, leisure sports activities can help leisure subjects realize the unification and harmony of bodies and minds, which is more in accord with leisure subjects' requirements in modern society.

\section{Leisure sports skill}

Leisure sports skill is the ability mastered and applied by leisure subjects in taking certain leisure sports activity. Leisure 
has become an important part of human life, which is an undoubted fact. People should prepare for leisure activities comprehensively, just as people prepare for work. In work, people with skills are more popular than that without skills. Similarly, in leisure sports, people with skills can easily taste pleasures and make progresses (Geoffrey Godbey, 2000, p197). The ideal leisure is a flexible continuous process, in which people devote themselves to leisure sports, learn from leisure sports, and achieve certain progresses.

Leisure sports, as an inevitable scientific relaxing way in modern life, have to depend on leisure sports skills. One of important characters of leisure sports is to realize relaxation with body exercises by different sports and activities. Any sports activity needs relevant sports skills and necessary physical fitness. Only when people grasp relevant skills and possess necessary physical fitness for certain sports activity, can they feel pleasures from this sports activity. A survey shows that one of important factors that stop people from joining in leisure sports is the absence of necessary skills and physical fitness. Although people realize that leisure sports are positive and scientific ways for leisure and also necessary leisure ways for modern social life, people can not take part in leisure sports due to lack of necessary skills and physical fitness. Even if people without necessary skills and physical fitness participate in leisure sports, they may give up finally because they can not get pleasures from it.

\section{Leisure sports state}

Leisure sports state refers to the physical and psychological sate of leisure subjects as they are engaged in leisure sports activities. One of values of leisure sports is to help people resume and relax bodies, enhance physical functions, obtain psychological satisfactions, get pleasures, and reach a high sense by means of leisure sports activities. That is a best experience of people in taking leisure or work activities. Similar to Maslow's "peak experience" or "peak expression", it is an extremely pleasure after realizing the self-fulfillment (Zhongguang Li \& Changchong Lu, 2004, p179). As a leisure subject know clearly how to use leisure sports skills, under certain pre-determined goal and principle constraint, to deal with all challenges anytime, a high sense may appear. At this moment, the leisure subject focuses attentions on one thing and does not care about any other problem. The self consciousness disappears. People even do not realize the existence of time.

As realizing a high sense, difficulties of challenges match the skills of leisure subject. If the challenge is too demanding, the leisure subject may feel worried. While the challenge is nothing, the leisure subject may feel boring. Leisure sports activity is to make people relax their bodies, resume physical functions, obtain pleasures, and reach a high sense. A beneficial leisure sports state will help to make certain leisure sports activity lasting.

\section{Reference}

Geoffrey Godbey. Translated by Kang, Zheng. (2000). Leisure in Your Life: An Exploration. Kunming: Yunnan People's Publishing House.

$\mathrm{Hu}$, Xiaoming. (2004). Theories and Practices of Sports Leisure Entertainment. Beijing: Higher Education Press.

John R. Kelly. Translated by Zhao, Ran. (2000). Freedom to Be: A New Sociology of Leisure. Kunming: Yunnan People's Publishing House.

Li, Guozhong \& Yang, Xueqin. (2007). Leisure Sports. Beijing: People's Sports Press.

Li, Zhongguang \& Lu, Changchong. (2004). Basic Leisure Studies. Beijing: Social Sciences Academic Press.

Lu, Feng. (2004). Discussion on the conception of leisure sports. Journal of Chengdu Sport University. No.30(5).

Lu, Feng. (2005). Leisure Physical Education. Beijing: People's Sports Press. p156.

Ma, Huidi. (2004). The Beautiful Spiritual Garden for Human Being. Beijing: China Economyic Publishing House.

Ma, Huidi. (2004). Leisure Economy: Entering Humanistic Care. Beijing: China Economic Publishing House.

Ma, Huidi \& Zhang, Jiang'an. (2004). An Investigation on the Public Leisure Conditions in China. Beijing: China Economic Publishing House.

Thomas Goodale \& Geoffrey Godbey. Translated by Cheng, Sumei. (2000). The Evolution of Leisure: Historical and Philosophical Perspectives. Kunming: Yunnan People's Publishing House.

Xi, Yubao. (2004). Discussion on leisure and leisure sports. China Sport Science and Technology. No.40(1). 